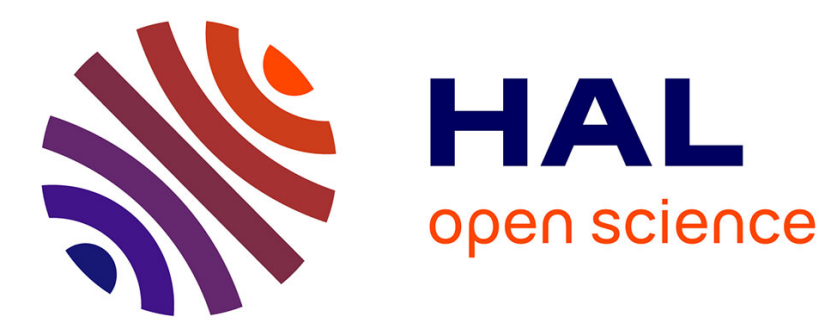

\title{
Overcoming Technical Constraints for Obtaining Sustainable Development with Open Source Appropriate Technology
}

\author{
Joshua Pearce, Usman Mushtaq
}

\section{To cite this version:}

Joshua Pearce, Usman Mushtaq. Overcoming Technical Constraints for Obtaining Sustainable Development with Open Source Appropriate Technology. 2009 IEEE Toronto International Conference Science and Technology for Humanity (TIC-STH 2009), Sep 2009, Toronto, Canada. 10.1109/TICSTH.2009.5444388 . hal-02120507

\section{HAL Id: hal-02120507 https://hal.science/hal-02120507}

Submitted on 6 May 2019

HAL is a multi-disciplinary open access archive for the deposit and dissemination of scientific research documents, whether they are published or not. The documents may come from teaching and research institutions in France or abroad, or from public or private research centers.
L'archive ouverte pluridisciplinaire HAL, est destinée au dépôt et à la diffusion de documents scientifiques de niveau recherche, publiés ou non, émanant des établissements d'enseignement et de recherche français ou étrangers, des laboratoires publics ou privés. 


\section{Overcoming Technical Constraints for Obtaining Sustainable Development with Open Source Appropriate Technology}

\author{
Joshua M. Pearce \\ Department of Mechanical and Materials Engineering \\ Queen's University \\ Kingston, ON \\ K7L 3N6 Canada \\ pearce@me.queensu.ca
}

\author{
Usman Mushtaq \\ Department of Civil Engineering \\ Queen's University \\ Kingston, ON \\ K7L 3N6 Canada \\ usman.mushtaq@queensu.ca
}

\begin{abstract}
Open source appropriate technology (OSAT) refers to technologies that provide for sustainable development while being designed in the same fashion as free and open-source software. Facilitated by advances in information technology software and hardware, new ways to disseminate information such as wikis and Internet-enabled mobile phones, the global development of OSAT has emerged as a reality. This paper shows the sharing of design processes, appropriate tools, and technical information is enables more effective and rapid development of appropriate technologies for both industrialized and non-industrialized regions. This sharing will require the appropriate technology community to adopt open standards/licenses, document knowledge, and build on previous work. This paper offers solutions in the form of both business models and tools to overcome technical constraints of OSAT development in the forms of the platforms necessary on which to share and build knowledge about appropriate technologies. These solutions are open, easily accessible for those in need, have a low barrier to entry for both users and information creators, and must be vetted in order to utilized as a trustworthy source on critical information needs. Current progress towards implementing these solutions will be reviewed and recommendations will be made to further increase the rate of OSAT development.
\end{abstract}

Keywords- appropriate technology; communication; development; information technology; open design; open hardware; open source; open source appropriate technology; OSAT; sustainability; sustainable development; wiki

\section{INTRODUCTION}

\section{A. Open source}

The open source movement emerged as a fundamentally new way to develop software in contrast to the closed box, industrial, and proprietary approach [1]. The movement called for a participatory and transparent system of software production by making the building blocks of software, source code, accessible to all. However, the goal of open source is more than just making source code available to the user. Open source must also include the "right to run the program for any purpose, to study how it works and adapt it to your own needs, to redistribute copies to others, and to improve the program and share your improvements with the community" (p. 5) [2]. It may also include requirements such as that all derivements have to be shared under the terms of the original work [3]. Through these principles of sharing and open-access, open source treats users as developers by encouraging contribution, recognizing good work through peer approval, and propagating improved code [4]. In open source development, there is no distinct line between users and developers and they are many times one and the same. All users can have their say in the development of a software solution as opposed to just a core group of developers. This decentralized method of software development is called the 'bazaar style' as opposed to the 'cathedral building' methods of professional software design [5]. In the bazaar, a variety of voices and agendas play out with each of them influencing decision-making. This philosophy of open access and bazaar style decision-making is enabled by the gift culture of open source, in which recognition of an individual is determined by the amount of knowledge givens away [6]. Similar to the gift culture of academia and the sciences, open source culture rewards contributors through a process of peer review. If the contributions of an individual are of merit, the contributor will have a greater say in the decisionmaking process of design. This type of reward is key to the continued success of the open source movement as it provides motivation for users to become excellent developers. Open source or open design is a method, which can also be used for the development of hardware (physical products, machines and systems) through use of publicly shared design information. In this paper, the specific hardware analyzed is appropriate technology.

\section{B. Appropriate technologies}

The term appropriate technology was popularized during the 1970's as a possible response to the great inequities of poverty in the world, particularly in the global South and the failures of development [7]. Many times, large-scale industrial 
development has created technology dependent on foreign aid, foreign expertise, and foreign perceptions. For example, the failure of large dams to encourage development is welldocumented by critics of international aid agencies. These critics have pointed out how $60 \%$ of the world's major rivers have had flows altered by dams and that millions of indigenous peoples have been relocated and ripped away from their lands only to see the dams fail if the are not subsidized by the state or private enterprise [8]. Client communities often have no capacity for these development efforts and so they would fail if external aid was withdrawn, making these communities dependent on aid. Some academics even came to see this dependency creating development as a new form of colonialism [9]. Seeing the failures of large-scale industrial development, academics and activists started to call for more context-aware and small-scale development involving appropriate technologies [10]. They believed that smaller, locally produced, and more "mundane" technology could tackle many of the problems of the global South that external aid had not solved. For example, they argued that simple decentralized point of use water sanitation systems requiring minute amounts of human and capital investment would be a more sustainable form of development than a centrally placed municipal sanitation system that would require enormous capital and human investments [11]. Backed by academics in the new appropriate technology school, NGOs and nonprofits started to use appropriate technology for sustainable development, since the technologies were low-tech, locally made, low-cost and contextually relevant for the client communities. Indeed, the concept of appropriate technology was a necessary precursor to the idea of sustainable development [12].

Although there are various formulations of appropriate technology [13], appropriate technology (AT) in this paper will be defined as those technologies that are easily and economically utilized from readily available resources by local communities in the developing world to meet their needs [14]. In addition, AT must meet the boundary conditions set by the environmental, cultural, economic, and educational resource constraints of the local community [15].

\section{Open source appropriate technologies}

Since global poverty is still a serious problem that affects not only countries in the global South, but also the industrialized global North [16], an urgent new way of thinking about appropriate technologies is needed. To that end, the concept of open source appropriate technology (OSAT) is proposed in this paper as a way to harness the power of distributed peer review, source transparency, and gift culture from the open source movement and the contextual development capacity of appropriate technologies. OSAT would allow technology users to be developers at the same time and share the open "source code" of their appropriate technologies. Instead of programming code, the "source code" for AT would be material lists, directions, specifications, designs, techniques, and scientific theories needed to build, operate, and maintain the appropriate technology. Users would be free to use and modify the "source code" (hereby referred to as source) from any shared appropriate technology. At the same time, users as developers would be engaging in a peer review process to determine the best practices and solutions to create appropriate technologies by sharing their modified source with other AT developers. The better a practice or solution was, the more it would be used and shared, thus giving the developer more recognition. It is predicted that the introduction of this gift culture in AT will have the same benefits for AT as it has had for the open source movement and academia.

The rise of peer to peer technology, wikis [17], social networking sites, folksonomies [18], and other Web 2.0 technologies allow user-developers of OSAT a wide range of platforms on which to create, share, and modify AT source. Wikis, in particular, have proven to be an excellent method through which to collaboratively articulate and share knowledge given the success of Wikipedia. In fact, there are several appropriate technology wikis currently in existence like the now merging Appropedia (primarily in English) [19] and Ekopedia (primarily in French) [20]. Even social networking sites like Ning have appropriate technology communities such as Global Swadeshi [21]. These technologies are an example of the appropriate technology movement applying its principles of open collaboration on the Internet.

\section{II.The CASE for open sourcing AT}

\section{A. Open source developement for more effective AT}

The open software movement has produced a community of hackers and computer programmers whose shared goal is to voluntarily work together to develop superior computer software for their use. They are motivated by many of the same reasons as other social movements such as the civil rights or labor movement [22]. Like individuals in those movements, open source advocates strongly believe in their cause, are extremely motivated, dedicate enormous quantities of their own time, and want to produce excellent products and results. Remarkably, an open-source community will even create better documentation, normally a low-priority and often hated activity among programmers, than paid and directed workers at a software company [23]. If open source software such as GNU/ Linux is compared against Microsoft's centralized and closed system of software development, a surprising result surfaces. A neutral technical assessment finds that open source software like Linux, developed mostly by unpaid volunteers, is of superior quality to the software developed by one of the most powerful companies in the world employing unquestionably intelligent people [24]. This remarkable result stands against conventional wisdom that would argue the profit motive and market forces would enable Microsoft to develop superior software to any random group of volunteers. Microsoft is a large company, with annual revenue of over $\$ 40$ billion, yet many of its products suffer from technical drawbacks that include bloat, lack of reliability, and security holes. Microsoft remains dominant largely because of inertia, but Linux eats up an ever larger market share (particularly in servers), because 
open source is simply more efficient and adaptable than closed, proprietary systems [25]. This is due in a large part because many more people collaborate on Linux than on Microsoft products. While Microsoft might utilize a few thousand programmers and software engineers to debug their code, the Linux community has access to thousands of user-developers debugging, rewriting, and submitting code. As Eric Raymond has said, "given enough eyeballs, all bugs are shallow" [26].

Linux is not the only example of open source success. Apache, open-source Web server software, has enjoyed tremendous popular success as well. In fact, Apache currently holds the largest market share for top servers across all Web domains surpassing corporate giants such as Microsoft and Google [27]. The success of these and other open source efforts have forced people to think about how open source may be applied outside the software domain. As the Agroblogger asked a few years ago when arguing for OSAT: "Now that Open Source has come of age, the question is not: Is it better than closed software? But rather: To what other systems, outside of software, can we apply the concepts of Open Source and public ownership?" [28].

\section{B. Open source to accelerate AT innovation}

Conventional wisdom would predict that the innovating ability of open source paradigms should not be able to compete with the highly successful and well demonstrated intellectual property system. Surprisingly, the counter argument comes from the gift culture of science that underpins the technologies that make up some of the free market's greatest success stories. Although the vast majority of scientists are employed by the free market, the science done is generally published for everyone else in a particular field to read. Merit is determined by the amount of knowledge given away rather than hoarded a key feature of all gift cultures [29]. This "open source" science is now being expanded beyond the ivory towers of the industrialized North to the rest of the world's population as the debate in academia is shifting to favor open access journals, which are available to any reader in the world on the internet. The primary advantage of open access is that the content is available to users everywhere regardless of affiliation with a subscribing library [58]. This benefits authors as they like to see their papers read more, cited more often, and better integrated into the structure of science [59]. It also accelerates the development of science as it enables academic readers at institutions that cannot afford the journal (as in many nations in the global South and researchers at smaller institutions with less comprehensive libraries). Finally, the general public, who will have the opportunity to learn what scientific research is underway, what their tax dollars often fund, and see how science effects their lives (e.g. patients can keep up with the latest medical research).

This system of gifting and open source stands in stark contrast to the system of copyright, patents and trademarks, which are often lumped together under the term of intellectual property (IP). Conventional IP law is designed to protect the intellectual property of individuals from unfair use by others by granting them a monopoly over the use of their property. Due to the exclusive monopoly rights governing IP, information is locked up and often prohibits or slows innovation, which is the exact opposite of the intended purpose of IP laws [30]. IP laws rewarding innovators for inventions or written work is meant to encourage innovation. However, the secrecy and anti-commons approach of the IP system has been found to limit knowledge sharing and development among academics, researchers, and innovators [31]. For example, patents and other IP protection may limit efforts in directions with high social value, but less commercial potential such as development of medicines that affect huge but poor populations [32]. Similar situations occur in the field of AT when the dominant IP system regulates it.

\section{Open source provides access to relevant AT}

Ethically intolerable global conditions demonstrate that there remains a marked underinvestment in sustainable development [33]. The optimists' position is that accelerated progress in technology will rescue society even from globalscale problems like climate destabilization. It is undeniable that technological development has provided great benefits to humankind in medicine and many other fields and technology is indeed developing faster now than ever before. Unfortunately, the vast majority of this technology is not focused on problems related to sustainable development and surprisingly, even much of it that is, is effectively removed from deployment by patent and copyright laws. The results of this restricted and closed model of technological development are the widespread poverty and environmental desecration seen around the globe, which is directly responsible for a morally and ethically unacceptable level of human suffering and death. For example, more than 10 million children under the age of five die each year from preventable causes [34]. This waste of human life could be prevented by known technologies, many of which are simply not available to those that need it. Availability is restricted by both the cost of access (such as pay-to-view peer-reviewed articles under copyright) and by companies wielding patent law to maximize profit at the cost of human lives (e.g. restricting the sale of antiretroviral drugs to treat HIV in Africa) [60]. A solution to this general problem of access to critical information for sustainable development would be to open source AT.

At the same time, open sourcing AT would allow people on the receiving end, the user-developer, to make the AT relevant for their use. In fact, the concept of AT was introduced precisely because it was felt that "ordinary people do not participate meaningfully in but, rather, are mainly controlled by" (p. 223) large-scale, privately controlled, capital, and resource intensive technology [35]. By privatizing AT through the IP system, ordinary people and user-developers could not participate meaningfully in creating AT. Only the owners of the IP rights to a specific AT could change or modify the AT, limiting innovation and local optimization. In the case of technology for sustainable development, this is an unavoidable moral and ethical dilemma. Is it acceptable to withhold information that could save the world's poorest people from unnecessary suffering and death? Is it acceptable to withhold 
information that could give the world's poorest a chance to shape their technological future? Vinay Gupta suggests that AT developers should agree to three principles: i) I will not permit any human being to be deprived of live-giving technology by the profit motive; ii) Any works that I patent I will make available to others who are engaged in humanitarian activity for free, except where this would breach other contractual responsibilities, iii) I will not use patent law to slow the pace of innovation or service delivery to the needy under any circumstances [36].

However, here we propose that open sourcing AT would be an even better way to ensure that the profit motive does not limit access, innovation, or localization.

\section{III.OPEN SOURCE LICENSING OPTIONS}

A variety of licensing options exist for open source code. These licenses were developed initially in response to unethical behavior within the open source software movement and, more importantly, to limit the commercializing of open source code so that it remained in the public domain [37]. The licenses did that by dictating that all derivatives from open source software would be subject to the same license as the original software and that closed and open source code could not be mixed. In a play of words from copyright, these original licenses came to be known as copyleft licenses. The General Public License (GPL), written by Richard Stallman, became one of the most popular copyleft licenses [38]. Since then, other licenses have been developed that allow the mixing of closed/open source code and even the commercializing of that code. A list of licenses is shown in Table 1 below.

\begin{tabular}{|c|c|c|c|c|}
\hline License & $\begin{array}{c}\text { Free } \\
\text { Software }\end{array}$ & Copyleft & $\begin{array}{c}\text { GPL } \\
\text { Compatible }\end{array}$ & Example \\
\hline Apache License 2.0 & Yes & No & Yes & Turbine \\
\hline $\begin{array}{c}\text { Original and } \\
\text { Modified BSD } \\
\text { Licenses }\end{array}$ & Yes & No & $\begin{array}{c}\text { Only } \\
\text { modified } \\
\text { version }\end{array}$ & Sendmail \\
\hline $\begin{array}{c}\text { GNU General } \\
\text { Public License }\end{array}$ & Yes & Yes & Yes & CVS \\
\hline $\begin{array}{c}\text { MIT license } \\
\text { License 1.1 }\end{array}$ & Yes & No & Yes & PuTTY \\
\hline $\begin{array}{c}\text { Common } \\
\text { Development and } \\
\text { Distribution } \\
\text { License }\end{array}$ & Yes & Yes & No & OpenSolaris \\
\hline $\begin{array}{c}\text { Common Public } \\
\text { License 1.0 }\end{array}$ & Yes & Weak & No & WiX toolset \\
\hline $\begin{array}{c}\text { Eclipse Public } \\
\text { License 1.0 }\end{array}$ & Yes & Weak & No & EclEmma \\
\hline
\end{tabular}

Table 1: Open Source licenses [39, 40]

In addition, documentation is necessary along with any source code for user-developers to understand it, so the open source community has created open documentation licenses.
These allow developers a way to ensure that documentation that may be necessary for the functionality and use of the open software also remains open. A list of the documentation licenses is shown in Table 2 below. These licenses cover all educational material related to an open source project so they do not just apply to text, but may also apply to video, audio, or art. In particular Creative Commons licenses can be tailored to provide attribution, share alike, non-commercial, no derivative works or any combination of the above.

The licenses that combine open/closed source code strategies are known as hybrid models [41]. These hybrid models combine the benefits of differentiation and control in IP with the accessibility and localization of open source. For example, Apple has used public source licenses to open up the lower levels of its operating system in order to allow third party add-ons. However, the core source code is still protected under the IP system. This has allowed people to localize and customize the Apple software while protecting the property interests of Apple.

\begin{tabular}{|c|c|c|c|c|}
\hline License & Free & Copyleft & $\begin{array}{c}\text { GFDL } \\
\text { Compatible }\end{array}$ & Example \\
\hline $\begin{array}{l}\text { GNU Free } \\
\text { Documentation } \\
\text { License }\end{array}$ & Yes & Yes & Yes & Wiktionary \\
\hline $\begin{array}{l}\text { Common } \\
\text { Documentation } \\
\text { License } 1.0\end{array}$ & Yes & Yes & No & Bonjour \\
\hline $\begin{array}{c}\text { FreeBSD } \\
\text { Documentation }\end{array}$ & Yes & No & Yes & FreeBSD \\
\hline $\begin{array}{c}\text { Open } \\
\text { Publication } \\
\text { License } 1.0\end{array}$ & Yes & Weak & No & $\begin{array}{l}\text { Advanced Bash- } \\
\text { Scripting Guide }\end{array}$ \\
\hline $\begin{array}{c}\text { Open Content } \\
\text { License } 1.0\end{array}$ & No & Yes & No & Nancies.org \\
\hline $\begin{array}{l}\text { Open } \\
\text { Directory } \\
\text { License }\end{array}$ & No & No & No & Dmoz.org \\
\hline $\begin{array}{l}\text { Creative } \\
\text { Commons } \\
\text { Attribution }\end{array}$ & Yes & No & No* & Change.gov \\
\hline $\begin{array}{l}\text { Design Science } \\
\text { License }\end{array}$ & Yes & Yes & No & $\begin{array}{l}\text { Fundamentals of } \\
\text { Electrical } \\
\text { Engineering and } \\
\text { Electronics }\end{array}$ \\
\hline $\begin{array}{l}\text { Free Art } \\
\text { License }\end{array}$ & Yes & Yes & No & $\begin{array}{c}\text { Free Art } \\
\text { Dictionary }\end{array}$ \\
\hline \multicolumn{5}{|c|}{$\begin{array}{l}\text { * The Creative Commons license CC-BY-SA } 3.0 \text { is compatible with } \\
\text { GNU-FDL if the work was produced on a "Massive Multiauthor } \\
\text { Collaboration Site", such as for example a public wiki. }\end{array}$} \\
\hline
\end{tabular}

Licensing is not just restricted to open source code though. Open source licensing has been discussed in the field of medicine [42] as well as nanotechnology [43]. Also, a license for open source hardware has been proposed [44]. This propagation of open licensing in other fields proves that the concept of open source does not have to be limited to software. Therefore, it would be feasible to use some existing licenses to create a Public Source License for appropriate technology or utilize the open source documentation licenses to propagate OSAT. 


\section{IV.Business Models of OSAT in UsE}

Most people of good will would be willing to take Gupta's pledge, but companies that do develop and profit from the sale of AT often can deliver affordable life affirming products and services to the 'bottom of the pyramid' using conventional mass scale manufacturing and business practices. How can they remain sustainable in the economic sense while opening their IP? Arduino, an Italian startup firm, has been manufacturing open hardware circuit boards and provides a model. They have had great success with the circuit boards partly because companies and individuals have been willing to hire them for their expertise in building systems on the open circuit board design provided by them. In this case, users are paying for the expertise of Arduino staff and not the actual product. At the same time, users are free to experiment, share, and modify the base product as they see fit. Arduino has posted everything related to their hardware on the Internet from software to circuit schematics. The response has been overwhelming with thousands of orders coming in for the circuit boards, which can be sold at a relatively low cost. Other users have just downloaded the schematics and built their own circuits boards. However, that has not stopped Arduino from being a sustainable enterprise [45].

As a second example, other entrepreneurs have brought the ideas of peer to peer software to banking. The Open Source Hardware Bank, which plans on being a federally regulated lending institution, connects small investors to specific open hardware projects. The bank is hoping to provide investors with a five to fifteen percent rate of return on their investments. At the same time, the cost of project failure is offset since there is a large pool of investors giving money to each project. In this peer to peer financing model, investors fund specific users and their projects hoping for a share of the return. Hardware developers have received the idea with great enthusiasm since open hardware projects typically require startup capital to buy material and resources unlike their open software counterparts [46].

One additional potential solution to this question comes from an unlikely source: Mrs. T's Pierogies. This is a small Pennsylvanian company that has a very successful business of selling pierogies (half circular dumplings of unleavened dough, stuffed with mashed potatoes and other ingredients) - they ship 11.4 million a week [47]. Recently, they volunteered all of the IP for the making of pierogies in a documentary by WQLN in the Made in Pennsylvania series: walked the viewer through their plant, and then showed step by step how to make a pierogie at home from scratch. At the end of the documentary they pointed out that although they showed you exactly how to make it, making pierogies is hard work and many people do not have the time...in that case consider buying Mrs. T's. A similar model could be followed for all AT, and the information necessary to provide the basic needs of the world's poorest could be open sourced. For example, a company making treadle pumps does not loose their market if they publish their schematics for those that would never be able to afford a manufactured treadle pump in the first place. Mrs. T's business model is protected in part from competition by the barrier to entry in their established market, the manufacturing process and equipment itself and supplier/distribution networks. ATbased companies would have similar protections for competition within their own markets. Although several models exist, it is clear that this concept needs further development, and will be left for future work.

Individuals, communities, and companies have already made important developments in open sourcing AT. One example is the open sourcing of appropriate technology to remove arsenic from drinking water in areas where clean water is not available [48, 49]. Another example of OSAT is the hexayurt, a temporary shelter, that could be used in refugee camps among other places. The creator of the hexayurt has posted directions, material lists, and test data on the Web that is freely accessible to all to use and modify [50].

A variety of distribution and business models have also been proposed for use with OSAT. One such model is the toolkit peer collaboration model in which user-developers are given the tools to innovate and share their ideas [51]. Instead of a developer trying to create user responsive AT, the userdevelopers could make their own AT using the tool-kits created by the developer. In this case, the developer could make profit through providing the tool-kits. Businesses may also engage with open source while making profit through providing services, widget frosting, or accessorizing [52]. For example, Red Hat, an example of a service provider, supports Linux, which is open source, through consulting and packaging. Other companies provide open source programs that may enhance the use of their hardware/software products, but the products themselves are proprietary. Finally, companies may provide complementary services or products that accessorize existing open source software. While they will not directly support open source office software, SUN Microsystems has developed complementary office applications to work alongside open source applications. However, the business world is not the only distribution model for OSAT. In academia, the use of service-learning in engineering courses could be used to create and distribute OSAT. This is laregly the work of groups like Engineers Without Borders, Engineers for a Sustainable World, and others. In addition, some work around virtual servicelearning to create and document OSAT has already taken place $[14,53,54]$. This work has shown that AT projects are highly engaging and motivational for the students $[15,53,55]$. These positive outcomes found with service learning for students are concomitant with the improved OSAT for sustainable development for both specific partner communities but also the rest of the world.

\section{V.Technical Limitations and Potential Solutions}

Despite the burgeoning list of successful deployments of AT based on OSAT principles for sustainable development several technical constraints need to be overcome in the future for OSAT to reach its full potential. First, because OSAT will be developed for/with the entire world population it must have multilingual support. This demands support of a large number 
of languages, which to date has been handled with relatively crude methods [54]. The majority of the large-scale wiki and collaborative websites enable multilingualism by spawning a separate and largely independent site for each language [56]. Current work at integrating multiple language sites between Appropedia and Ekopedia provide a partial solution but further software development is needed to truly allow collaboration on OSAT among the languages.

Most importantly, there must be a method to verify the integrity of OSAT designs. Similar to an online store (e.g. Amazon.com), there must be a degree of product information accompanied by successful customer reviews or testimonials before one can be expected to invest in AT. This currently is handled in the OSAT wikis by a soft system where AT that did not function up to specifications would be presumably fixed by directly editing the page or discussed by user/contributors. This is a relatively inefficient method before a critical mass of motivated users has been established. A new method that guarantees the rigor of the designs must be developed. This could take the form of a more formal review and rating system for documented innovations themselves and for the reviewer/developers. Like eBay's feedback points, experienced innovators can foster a reputation for developing high quality appropriate technologies. Through user reviews and scoring, successful innovations can be quickly referenced while unproven or unwanted content can be easily avoided by display rankings similar to Google's listing the most relevant search string first. Here, the most highly ranked innovation to solve a particular sustainable developmental problem or of a particular device design would be provided to users before less proven designs. The software to overcome these challenges has not yet been written by the OSAT community, but the problems might be solved in the short term using an organizational certification system to convey trust and overcome barriers to innovation diffusion and information adoption. Similar to a Consumer Reports stamp of approval, organizations already well known in the AT space (e.g. Engineers Without Borders Canada) specializing in particular appropriate technologies will be given certification power. This is a non-optimal technical solution, because although it would provide some needed assurance of device design quality, it would necessarily slow the rate of innovation and restrict the full capacity of the global human system to solve sustainable development problems.

Finally, because many ATs are necessarily geographically dependent, it is imperative that geographic information systems (GIS) are developed to allow OSAT to be searched spatially as well as by keyword and browsing functions. Currently, there is some preliminary work with openstreetmap.org and utilizing Google Earth based free software to enable the coordination of industrial symbiosis and reduced embodied energy of transportation [57]. This work can be expanded to enable cross referencing OSAT with GIS systems to create adaptive searching for culturally, ecologically, and economically relevant technologies for any community.

\section{VI.ConClusions}

It is ironic, in a time where the basic tools for information production in form of computers and the internet are now available to over 1 billion people and growing daily, the law still favors capital-intensive industries over individuals and small businesses. Appropriate technology development could benefit greatly from the application of an open source model. Throughout the world there exists research institutes, community groups, and non-governmental organizations working with different technological innovations to alleviate poverty and mitigate the destruction caused by excesses of consumer culture. For the most part they remain disconnected, often re-inventing the proverbial wheel again and again although their counterparts in another part of the world may have already designed and debugged a similar technology. Consider the effect of OSAT reaching critical mass and creating a vibrant virtual community to share AT plans and experiences. OSAT would enable designers and field workers to download plans of water pumps, wind mills, basic medicines, passive solar, and many other appropriate technologies. OSAT would fall within the legal framework of an AT General Public License, where those plans can be used freely, modified, and republished under the same AT GPL for those in the future all over the world to benefit from. In this way, open source appropriate technology will become a true rival to the paradigms of the development of technology that have dominated civilization since the industrial revolution. A new revolution, built on a dispersed network of innovators, inventors, and researchers working together to create a just sustainable world will be created.

\section{REFERENCES}

[1] A. Mockus, R.T. Fielding, and J.D. Herbsleb, "Two cases studies of open source software development: Apache and Mozilla," ACM Transactions on Software Engineering and Methodology, vol. 11, no. 3, pp. 309-346, 2002.

[2] S. Weber, "Open source software in developing economies", Accessed at:http://www.ssrc.org/programs/itic/publications/ITST_materials/weber note2.pdf on April 30, 2009.

[3] M. Hansen, K. Kohntopp, and A. Pfitzmann, "The open source approach - opportunities and limitations with respect to security and privacy," Computers \& Security, vol. 21, no. 5, pp. 461-471, 2002.

[4] S. Weber, "The political economy of open source software," Berkeley Roundtable on the International Economy, Working Paper 140, 2000.

[5] E.S. Raymond, "The cathedral and the bazaar," First Monday, vol. 3, no. 3, 1998.

[6] M. Bergquist and J. Ljungberg, "The power of gifts: organizing social relationships in open source communities," Information Systems Journal, vol. 11, pp. 305-320, 2001.

[7] C. Pursell, "The rise and fall of the appropriate technology movement in the United States, 1965-1985," Technology and Culture, vol. 34, no. 3, pp. 629-637, 1993.

[8] International Rivers Network, "Spreading the water wealth: making water infrastructure work for the poor," IRN Dams, Rivers, \& People 2006, Berkeley, CA: 2006.

[9] A. Escobar, Encountering development: the making and unmaking of the third world, 1945-1992. Princeton, NJ: Princeton University Press, 1995.

[10] E.F. Schumacher, Small is beautiful: a study of economics as if people mattered. New York, US: Harper and Row, 1973.

[11] E. Mintz, J. Bartram, P. Lochery, and M. Wegelin, "Not just a drop in the bucket: expanding access to point of use water treatment systems," 
American Journal of Public Health, vol. 91, no. 10, pp. 1565-1570, 2001.

[12] J. DuBose, J.D. Frost, J.A. Chamaeau, and J.A. Vanegas, "Sustainable development and technology," In The Environmentally Educated Engineer, D. Elms and D. Wilkinsin (eds). Canterbury: Center for Advanced Engineering, 1995.

[13] C. Pursell, "The rise and fall of the appropriate technology movement in the United States, 1965-1985," Technology and Culture, vol. 34, no. 3, pp. 629-637, 1993.

[14] J. M. Pearce, "Teaching physics using appropriate technology projects", The Physics Teacher, vol. 45, pp. 164-167, 2007.

[15] J. M. Pearce, "Teaching science by encouraging innovation in appropriate technologies for sustainable development", Proceedings of the $11^{\text {th }}$ Annual National Collegiate Inventors and Innovators Alliance Conference, pp.159-167, 2007.

[16] A. Shah, Poverty Facts and Stats. Accessed at:http://www.globalissues.org/article/26/poverty-facts-and-stats, 2008.

[17] C. Wagner, "Wiki: a technology for conversational knowledge management and group collaboration," Communications of the Association for Information Systems, vol. 13, 2004.

[18] A. Mathes, "Folksonomies - cooperative classification and communication through shared metadata," Accessed at: http://www.adammathes.com/academic/computer-mediatedcommunication/folksonomies.html, 2004.

[19] Appropedia. Accessed at: http://www.appropedia.org on April 23, 2009.

[20] Ekopedia. Accessed at: http://www.ekopedia.org on April 30, 2009.

[21] Global Swadeshi. Accessed at: http://www.globalswadeshi.net/ on April 24, 2009.

[22] G. Hertel, S. Niedner, and S. Herrmann, "Motivation of software developers in open source projects: an internet-based survey of contributors to the Linux kernel," Research Policy, vol. 32, pp. 1159-1177, 2003.

[23] K.R. Lakhani and E.V. Hippel, "How open source software works: "free" user-to-user assistance," Research Policy, vol. 32, p. 923-943, 2003.

[24] A. Bonaccorsi and C. Rossi, "Why open source software can succeed," Research Policy, vol. 32, pp. 1243-1258, 2003.

[25] B. Kogut and A. Metiu, "Open-source software development and distributed innovation," Oxford Review of Economic Policy, vol. 17, no. 2, 248-264, 2001

[26] E.S. Raymond, "The cathedral and the bazaar," First Monday, vol. 3, no. 3, 1998.

[27] Netcraft, The 2009 Netcraft Web Server Survey. Accessed at: http://news.netcraft.com/archives/web_server_survey.html Apr.23, 2009.

[28] Agroblogger, Open sourcing appropriate technology. Accessed at: http:// www.agroblogger.com/2005/11/17/open-sourcing-appropriatetechnology-part-i/ on April 23, 2009.

[29] M. Bergquist and J. Ljungberg, "The power of gifts: organizing social relationships in open source communities," Information Systems Journal, vol. 11, pp. 305-320, 2001.

[30] B. Kogut and A. Metiu, "Open-source software development and distributed innovation," Oxford Rev. of Econ. Policy, vol. 17, no. 2, 248-264, 2001.

[31] R. P. Merges and R. R. Nelson, "On the Complex Economics of Patent Scope," Columbia Law Review, vol. 90, no. 4, pp. 839-916, 1990.

[32] S.M. Maurer, A. Rai, and A. Sali, "Finding cures for tropical diseases: is open source an answer?," PLoS Med, vol. 1, no. 3, e56, 2004.

[33] World Commission on Environment and Development, Our Common Future. New York, NY: Oxford University Press, 1987.

[34] R. E. Black, S.S. Morris, and J. Bryce, "Where and why are 10 million children dying every year?," The Lancet, vol. 361, pp. 2226-2234, 2003.

[35] D.E. Morrison, "Soft tech/hard tech, hi tech/lo tech: a social movement analysis of appropriate technology," Sociological Inquiry, vol. 53, no. 2-3, pp. 220-248, 1983.

[36] V. Gupta, "Starting an anti-patent-abuse appropriate technology political bloc?," Global Swadeshi. Posted on July 23, 2008. Accessed at: http://www.globalswadeshi.net/forum/topic/show? $\mathrm{id}=2097821 \% 3 \mathrm{AT}$ Topic\%3A2401: on April 23, 2009.

[37] J. Lerner and J. Tirole, "The scope of open source licensing," The Journal of Law, Economics, and Organization, vol. 21, no. 1, pp. 20-56, 2005 .

[38] Free Software Foundation, "GNU General Public License," version 3 June 29, 2007. Accessed at: http://www.gnu.org/licenses/gpl-3.0.txt on April 23, 2009.

[39] M.W. Wu and Y.D. Lin, "Open source software development: an overview," Computer, vol. 34, no. 6, pp. 33-38, 2001.

[40] Free Software Foundation, "Open Licenses," 2008. Accessed at: http:// www.gnu.org/licenses/licenses.html on April 29, 2009.

[41] J. West,"How open is open enough?Melding proprietary and open source platform strategies"Research Policy, vol.32, pp.1259-1285, 2003.

[42] A. Kapczynski, S. Chaifetz, Z. Katz, and Y. Benkler, "Addressing global health inequities: an open licensing approach for university innovations," Berkeley Technology Law Journal, vol. 20, pp. 1031-1114, 2005

[43] B. Bruns, "Open sourcing nanotechnology research and development: issues and opportunities," Nanotechnology, vol. 12, pp. 198-210, 2001.

[44] J. Ackermann, "TAPR Open Hardware License," TAPR. Accessed at: http://www.tapr.org/ohl.html on April 27, 2009.

[45] C. Thompson, "Build it. Share it. Profit. Can open source hardware work?" Wired Magazine, 16.11, 2008.

[46] P. Ganapati, "Open source hardware hackers start P2P bank," Wired Magazine, Gadget Lab, 2009. Accessed at: http://www.wired.com/gadgetlab/2009/03/open-source-har Apr29, 2009.

[47] Mrs. T's Pierogies. Accessed at: http://www.pierogies.com/retail/aboutus.asp on April 30, 2009.

[48] M. Lounsbury, C. Kelty, C. T. Yavuz and V. L. Colvin "Towards open source nano: arsenic removal and alternative models of technology transfer," Technology, Innovation, and Institutions Working Paper Series. TII-1-2008, 2008.

[49] F. Hashmi and J. M. Pearce, "Viability of Small-Scale ArsenicContaminated Water Purification Technologies for Sustainable Development in Pakistan", vol. 17, Sustainable Development, 2009.

[50] Hexayurt, Accessed at: http://hexayurt.com/ on April 27, 2009.

[51] E. Hippel and R. Katz, "Shifting innovation to users via toolkits," MIT Working Paper. Accessed at http://userinnovation.mit.edu/papers/10.pdf: on April 23, 2009.

[52] M. Mustonen,"Copyleft - the economics of Linux and other open source software,'Information Economics \& Policy, vol.15, pp.99-121, 2003.

[53] J. M. Pearce, "Appropedia as a tool for service learning in sustainable development", Journal of Education for Sustainable Development, vol. 3, (in press) 2009.

[54] E. ter Horst and J.M. Pearce, "Foreign Languages and the Environment: A Collaborative Instructional Project:", The Language Educator, pp. 5256, October, 2008.

[55] J. M. Pearce, L. Grafman, T. Colledge, and R.Legg, "Leveraging information technology, social entrepreneurship and global collaboration for just sustainable development" Proceedings of the $12^{\text {th }}$ Annual National Collegiate Inventors and Innovators Alliance Conference, pp. 201- 210, 2008.

[56] A. Désilets, L. Gonzalez, S. Paquet, M. Stojanovic, "Translation the Wiki Way," International Proceedings of WikiSym 2006. Odense, Denmark: August 21-23, 2006.

[57] J. M. Pearce, S. J. Johnson, and G. B. Grant, "3D-Mapping Optimization of Embodied Energy of Transportation", Resources, Conservation and Recycling, vol. 51, pp. 435-453, 2007.

[58] D. Malakoff, "Opening the books on open access: this month the Public Library of Science unveiled a free electronic, open-access journal based on author fees. Will this financial model work?", Science, vol. 302, no. 5645 , pp. 550-555, 2003.

[59] K. Antelman, "Do open-access articles have a greater research impact?", College and research libraries, vol. 65, no. 5, pp. 372-382, 2004.

[60] Y. Shantharam, "The cost of life: patent laws, the WTO, and the HIV/AIDS pandemic", Undercurrent, vol. 2, no. 2, pp. 48-56, 2005 